\title{
Bioactivity of Cicuta virosa L. var. latisecta Celak. (Umbelliferae: Cicutal) against Red Imported Fire Ant under Laboratory and Field Conditions
}

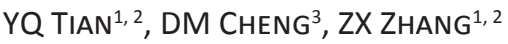 \\ 1 - State Key Laboratory for Conservation and Utilization of Subtropical Agro-Bioresources, Guangzhou, China \\ 2 - South China Agricultural University, Guangzhou, China \\ 3 - Zhongkai University of Agriculture and Engineering, Guangzhou, China
}

\author{
Article History \\ Edited by \\ Evandro do Nascimento Silva, UEFS, Brazil \\ Received \\ Initial acceptance \\ Final acceptance \\ 16 July 2014 \\ 14 May 2015 \\ 15 May 2015

\section{Keywords} \\ Cicuta virosa L. var. latisecta, isoimperatorin, \\ Solenopsis invicta, insecticidal activity.

\section{Corresponding author} \\ Zhixiang Zhang \\ College of Natural Resourcesand Environment, \\ South China Agricultural University \\ Wushan, Tianhe, Guangzhou 510640, \\ People's Republic of China \\ E-Mail: zdsys@scau.edu.cn
}

\begin{abstract}
We have evaluated the bioactivities of compounds from Cicuta virosa L. var. latisecta Celak. against red imported fire ants (Solenopsis invicta Buren) under field and laboratory conditions. The compounds were as follows: methanol extract; petroleum ether, chloroform, and ethyl acetate fractions from the methanol extract; and the active compound isoimperatorin, which was isolated from the chloroform-fraction. The $7 \mathrm{~d} \mathrm{LC}_{50}$ values of the methanol extract, petroleum ether, chloroform, and ethyl acetate fractions and isoimperatorin toward micrergates were $111.20,214.45,40.90,569.67$, and $25.73 \mathrm{mg} / \mathrm{kg}$, respectively. The corresponding $\mathrm{LC}_{50}$ values toward macrergates were 155.78, $308.38,75.01,776.75$, and $42.77 \mathrm{mg} / \mathrm{kg}$, respectively. Under field conditions, baits containing $0.2 \%$ methanol extract, $0.1 \%$ chloroform fraction, and $0.05 \%$ isoimperatorin efficiently controlled $S$. invicta, with effectiveness percentages of $95.56 \%, 97.78 \%$, and $95.56 \%$, respectively on the 30th day after bait application. Such effectiveness percentages were not significantly different from that obtained using the positive control fipronil. The present study showed that $C$. virosa L. var. latisecta has potential as a natural control agent for the red imported fire ants.
\end{abstract}

\section{Introduction}

The red imported fire ants, Solenopsis invicta Buren (Hymenoptera: Formicidae), is an exotic invasive pest ant species that has spread in many countries, including China. The imported fire ant workers sting and inject venom, which make them medically important insects (deShazo et al., 1999). Less than $3 \%$ of the human population is sensitive to the venom of fire ants, but stinging incidences have resulted in serious medical problems or even death, particularly when the victim is young, old, or has a compromised immune system (Drees et al., 2013). The fire ant has become a dominant pest in invaded areas, causing great economic loss and ecological problems.

Efforts have been made to control the red imported fire ants. Insecticide use is an important control strategy. Fipronil is a broad-spectrum pyrazole insecticide that could serve as a bait toxicant for control of ants. A $15 \mu \mathrm{g} / \mathrm{mg}$ granular bait caused over $80 \%$ colony mortality at 6 and 12 weeks after broadcast application in non-grazed pastures (Collins \& Callcott, 1998). The activities of other insecticides, such as bifenthrin, chlorfenapyr, and thiamethoxam were also evaluated against red imported fire ants (Wiltz et al., 2010). Biological control is also an important pest management method for this species. Biological control strategies include the use of the following: Pseudacteon spp. (Diptera: Phoridae) parasitoids; Kneallhazia solenopsae (Microsporidia: Tubulinosematidae) (Williams et al., 1999), which is the causative agent of fire ant disease; Beauveria bassiana (Balsamo) Vuillem (Bextine \& Thorvilson, 2002; Oi et al., 1994); and insect viruses (Valles \& Strong, 2005; Hashimoto \& Valles, 2008).

Plants contain many compounds that have insecticidal activities. Many of these compounds have been used as alternatives to synthetic chemical pesticides because of their desirable attributes, such as eco-friendly nature, availability, 
safety, acceptability, minimal effect on beneficial organisms, low cost, good storage, and easy application. Many plant-derived compounds have been widely used as commercial formulations, such as rotenone from the roots of Derris trifoliata Lour. and azadirachtin from the fruits of Azadirachta indica A. Juss. Plantderived substances are globally known because they have few side effects and have insect control properties. However, information is lacking on the activities of plant-derived compounds against red imported fire ants. In our study on natural insecticides of plant origin, we obtained a methanol extract from Cicuta virosa $\mathrm{L}$. var. latisecta Celak, which is a perennial herbaceous plant growing in Northeast China; this plant is a Chinese folk medicine used to treat abdominal pain ( $\mathrm{Li}$ et al., 2009) and has potency against the red imported fire ants. We analyzed the bioactivities of the methanol extract, fractions (petroleum ether, chloroform, and ethyl acetate fractions), and an isolated active compound, namely, isoimperatorin against fire ants under laboratory and field conditions.

\section{Material and Methods}

\section{Preparation of plant extract, fractions and isoimperatorin}

The whole plant of $C$. virosa L. var. latisecta Celak was collected from the suburbs of Changchun, Jilin Province, China in June 2013 and was air-dried at room temperature. Methanol extract and fractions from the plant and isoimperatorin were prepared according to the author's previously reported method (Tian et al., 2013). The powdered dry plant material was extracted with methanol at room temperature, and the methanol solution was concentrated in vacuo. The residue was sequentially extracted with petroleum ether, chloroform $\left(\mathrm{CHCl}_{3}\right)$, and ethyl acetate (EtOAc). The resulting petroleum ether, $\mathrm{CHCl}_{3}$, and EtOAc solutions yielded a deep brown syrup after concentration in vacuo. The active compound isoimperatorin was isolated from the $\mathrm{CHCl}_{3}$-soluble extract using the same procedure described by the author in the abovementioned reference.

Origin and rearing of micrergate and macrergates of red imported fire ants

S. invicta colonies were collected from the suburbs of Guangzhou, China and maintained in the laboratory for bioassays (Lv et al., 2006; Huang et al., 2007). The collected ants were fed with a mixture of $10 \%$ honey and live insects (Tenebrio molitor L.). A test tube $(25 \mathrm{~mm} \times 200 \mathrm{~mm})$ partially filled with water and plugged with cotton was used as a water source. The ants were maintained in the laboratory at $25 \pm 2{ }^{\circ} \mathrm{C}$.

\section{Preparation of fire ant bait}

C. virosa L. var. latisecta methanol extract, the three abovementioned fractions, and isoimperatorin were mixed with fire ant bait for bioassays under laboratory and field conditions. The bait was prepared as described by Kafle et al. $(2010,2011)$ with some modifications. At first, the extract, fractions, and isoimperatorin were dissolved in acetone. Subsequently, the acetone solutions were mixed with soybean oil, shrimp shell, and corn powders. Finally, the prepared baits were placed in a ventilating cabinet for $1 \mathrm{~h}$. The baits were maintained in a refrigerator $\left(4^{\circ} \mathrm{C}\right)$ for future use after the acetone had evaporated.

\section{Laboratory bioassays}

The vertical wall of a beaker with a bottom diameter of $10 \mathrm{~cm}$ was coated with Fluon emulsion after drying for $24 \mathrm{~h}$ to prevent the ants from escaping. This beaker was used as a foraging area. The artificial baits were placed $2 \mathrm{~cm}$ away from the inner wall of the beaker. A test tube was filled with water to approximately two-thirds full. The test tube was tightly plugged with water-saturated cotton, which was pushed $3 \mathrm{~cm}$ into the mouth of the test tube. The test tube was placed inside each beaker to serve as the water source for the insects.

All ants used in the toxicity tests were from the same colony. A group of 30 micrergates or macrergates was transferred into the beaker for the toxicity tests, and each test was replicated thrice. The baits, which contained the abovementioned methanol extract, fractions, or isoimperatorin at serial concentrations were placed in the beakers for the bioassay. A blank bait mixed with only acetone was used as the negative control. The mortalities were corrected by Abbott's formula (Abbott, 1925). The average corrected mortality of three replications at each concentration was calculated $7 \mathrm{~d}$ later. The $\mathrm{LC}_{50}$ value, which is the concentration that causes $50 \%$ insect mortality, was determined using probit analysis.

During the tests, mortality was recorded at an interval of $48 \mathrm{~h}$ for $7 \mathrm{~d}$. This study was conducted under ambient temperature and relative humidity, as follows: $27 \pm 1^{\circ} \mathrm{C}$ and 60 $\pm 5 \% \mathrm{RH}$ on average under $14 \mathrm{~h}: 10 \mathrm{~h}$ light : dark photoperiod.

\section{Field trials}

The effectiveness of $C$. virosa $L$. var. latisecta baits containing methanol extract, chloroform fraction, and isoimperatorin on the inactivation of $S$. invicta mounds were evaluated under field conditions. The field studies were conducted in the Zengcheng Farm of South China Agricultural University. The experiment was designed in a single factor random block. Fifteen mounds were used for each bait and for control treatments. Each treatment was replicated thrice. The baits were sprinkled around a $50 \mathrm{~cm}$ radius from the mounds' center. The commercial insecticide fipronil (purity 96\%, Tuo Qiu Agricultural Chemical Ltd. Co., Jiangshu Province, China) was used as the positive control. The blank bait mixed with only acetone was used as the negative control. The number of active mounds in the field was determined on the 1st, 5th, 10th, 20th, and 30th days after 
treatment. A mound was designated as active when at least 20 adult workers exited the excavated soil when probed with a metal rod (5 mm in diameter) (Kafle et al., 2011). The control effectiveness was calculated using the following equation:

control effectiveness $=\left[\left(\mathrm{S}_{\text {control }}-\mathrm{S}_{\text {treatment }}\right) /(100-\right.$ $\left.\left.\mathrm{S}_{\text {control }}\right)\right] \times 100$, where $\mathrm{S}=$ (number of active mounds before treatment - number of active mounds after treatment)/number of active mounds before treatment $\times 100$.

\section{Statistical analyses}

The results were expressed as mean \pm standard error. The treatment means were transformed into arcsine squareroot values for analysis of variance (ANOVA). The means were compared and separated by Scheffe's test. $\mathrm{P}<0.05$ was the level of statistical significance.

\section{Results and Discussion}

\section{Laboratory bioassays}

C. virosa L. var. latisecta methanol extract and fractions (petroleum ether, $\mathrm{CHCl}_{3}$, and $\mathrm{EtOAc}$ ) and isoimperatorin showed insecticidal activities against micrergates of red imported fire ants (Fig 1). The insecticidal activities were

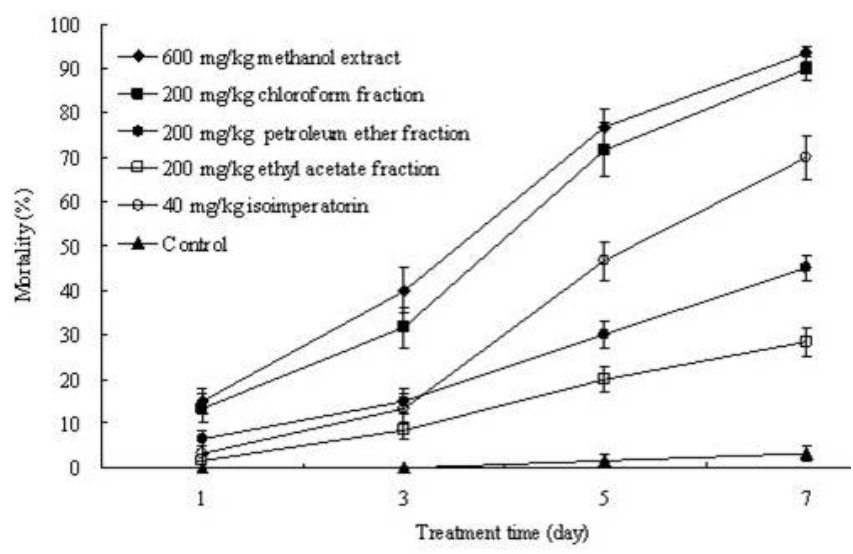

Fig 1. Mortalities of Cicuta virosa L. var. latisecta methanol extract, fractions and isoimperatorin against micrergates of Solenopsis invicta under laboratory conditions. slow to show, but the corrected percentage mortalities of treated micrergates increased steadily with increasing treatment time. Seven days after the treatment, the highest mortality $(93.33 \%)$ occurred among the micrergates treated with $600 \mathrm{mg} / \mathrm{kg}$ methanol extract. The micrergate mortalities under the other treatments were in the following descending order: $200 \mathrm{mg} / \mathrm{kg}$ chloroform fraction $(90.00 \%), 40 \mathrm{mg} / \mathrm{kg}$ isoimperatorin $(70.00 \%), 200 \mathrm{mg} / \mathrm{kg}$ petroleum ether fraction $(45.00 \%), 200 \mathrm{mg} / \mathrm{kg}$ ethyl acetate fraction $(28.33 \%)$, and the control (3.33\%). The $7 \mathrm{~d} \mathrm{LC}_{50}$ values of the methanol extract and fractions (petroleum ether, $\mathrm{CHCl}_{3}$, and EtOAc) and isoimperatorin for the micrergates were 111.20, 214.45, 40.90, 569.67, and $25.73 \mathrm{mg} / \mathrm{kg}$, respectively (Table 1).

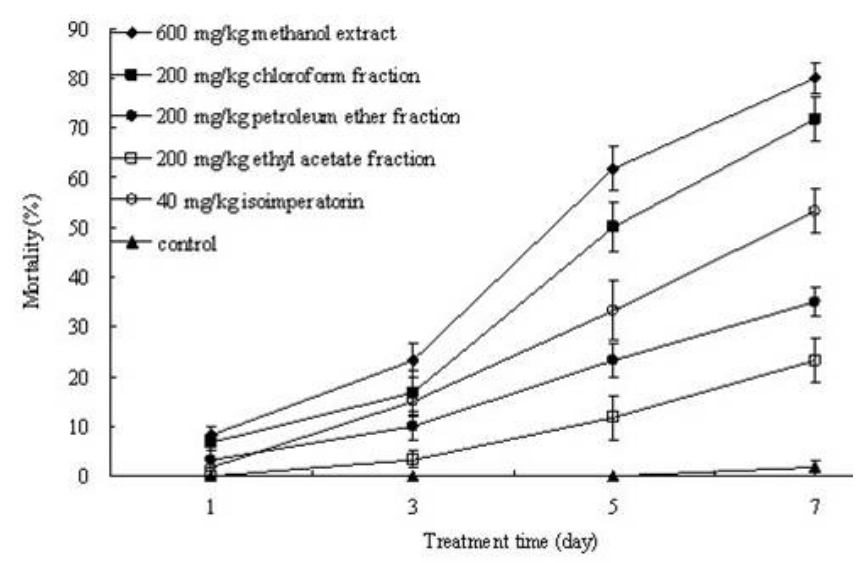

Fig 2. Mortalities of Cicuta virosa L. var. latisecta methanol extract, fractions and isoimperatorin against macrergates of Solenopsis invicta under laboratory conditions.

For the macrergates, similar trends were observed (Fig 2). The $600 \mathrm{mg} / \mathrm{kg}$ methanol extract resulted in the highest mortality $(80.00 \%)$ at $7 \mathrm{~d}$ after treatment. The mortalities induced by the other treatments were in the following decreasing order: $200 \mathrm{mg} / \mathrm{kg}$ chloroform fraction $(71.67 \%), 40 \mathrm{mg} / \mathrm{kg}$ isoimperatorin $(53.33 \%), 200 \mathrm{mg} / \mathrm{kg}$ petroleum ether fraction $(35.00 \%), 200 \mathrm{mg} / \mathrm{kg}$ ethyl acetate fraction $(23.33 \%)$, and the control (1.67\%). The $7 \mathrm{~d} \mathrm{LC}_{50}$ values of the methanol extract and fractions (petroleum ether, $\mathrm{CHCl}_{3}$, and $\mathrm{EtOAc}$ ) and isoimperatorin for macrergates were 155.78, 308.38, 75.01, 776.75 , and $42.77 \mathrm{mg} / \mathrm{kg}$, respectively (Table 2).

Table 1. LC50 of Cicuta virosa L. var. latisecta methanol extract, petroleum ether-, chloroform- and ethyl acetate fractions, and isoimperatorin against micrergates of Solenopsis invicta.

\begin{tabular}{llccc}
\hline Treatment & Regression equation & $\mathrm{LC}_{50}(\mathrm{mg} / \mathrm{kg})$ & $\mathbf{9 5 \% \text { Fiducial limit }}$ & Correlation coefficients \\
\hline Methanol extract & $\mathrm{Y}=1.3499+1.7839 \times$ & 111.20 & $89.76 \sim 137.76$ & 0.9917 \\
Petroleum ether fraction & $\mathrm{Y}=0.8122+1.7963 \times$ & 214.45 & $175.07 \sim 262.69$ & 0.9868 \\
Chloroform fraction & $\mathrm{Y}=2.0932+1.8035 \mathrm{x}$ & 40.90 & $33.26 \sim 50.29$ & 0.9907 \\
Ethyl acetate fraction & $\mathrm{Y}=-0.0535+1.8339 \mathrm{x}$ & 569.67 & $466.83 \sim 695.18$ & 0.9966 \\
Isoimperatorin & $\mathrm{Y}=2.4614+1.7999 \mathrm{x}$ & 25.73 & $21.03 \sim 31.48$ & 0.9898 \\
\hline
\end{tabular}


Table 2. LC50 of Cicuta virosa L. var. latisecta methanol extract, petroleum ether-, chloroform- and ethyl acetate fractions, and isoimperatorin against macrergates of Solenopsis invicta.

\begin{tabular}{lcc|c|c}
\hline Treatment & Regression equation & $\mathbf{L C}_{50}(\mathbf{m g} / \mathbf{k g})$ & 95\% Fiducial limit & Correlation coefficients \\
\hline Methanol extract & $\mathrm{Y}=1.2080+1.7295 \mathrm{x}$ & 155.78 & $126.60 \sim 191.67$ & 0.9946 \\
Petroleum ether fraction & $\mathrm{Y}=0.0045+2.0070 \mathrm{x}$ & 308.38 & $256.17 \sim 371.23$ & 0.9899 \\
Chloroform fraction & $\mathrm{Y}=1.9671+1.6174 \mathrm{x}$ & 75.01 & $58.85 \sim 95.61$ & 0.9938 \\
Ethyl acetate fraction & $\mathrm{Y}=-0.5601+1.9237 \mathrm{x}$ & 776.75 & $636.97 \sim 947.18$ & 0.9902 \\
Isoimperatorin & $\mathrm{Y}=1.9383+1.8771 \mathrm{x}$ & 42.77 & $35.08 \sim 52.13$ & 0.9907 \\
\hline
\end{tabular}

\section{Field trials}

C. virosa L. var. latisecta methanol extract, chloroform fraction, and isoimperatorin could control S. invicta, but these botanical insecticides were slower to act than fipronil (Table 3). On the 5th day after bait application, the control effectiveness of baits containing $0.2 \%$ methanol extract, $0.1 \%$ chloroform fraction, and $0.05 \%$ isoimperatorin were $33.33 \%, 31.11 \%$, and $26.67 \%$, respectively. These results were significantly lower than the positive control fipronil (66.67\%) $(\mathrm{F}=14.297$, $\mathrm{P}=0.0039$ ). On the 10th day, the control effectiveness value of $0.01 \%$ fipronil-based bait was still significantly higher than the three baits $(\mathrm{F}=11.407, \mathrm{P}=0.0068)$. However, on the 30 th day, the control effectiveness of the baits containing methanol extract, chloroform fraction, and isoimperatorin increased to $95.56 \%, 97.78 \%$, and $95.56 \%$, respectively, and such percentages were not significantly different from the control effectiveness percentage of fipronil bait $(100 \%)(\mathrm{F}=2.2, \mathrm{P}$
$=0.1889)$. However, the control value of $0.01 \%$ fipronil bait treatment remained the highest throughout the $30 \mathrm{~d}$ period after bait application.

In the present study, the bioactivity of the insecticidal plant (C. virosa var. latisecta) against the red imported fire ant was investigated. The crude methanol extract and fractions (petroleum ether, $\mathrm{CHCl}_{3}$, and EtOAc) and the isolated compound isoimperatorin were verified to be active against micrergates and macrergates of the ants under both laboratory and field conditions. C. virosa L. var. latisecta compounds are safe for use as control agents of fire ants. C. virosa $\mathrm{L}$. var. latisecta is used in Northeast China to control aphids on vegetables. Furthermore, the isolated active compound, isoimperatorin, is also a main active constituent in other safe-for-use traditional Chinese medicinal plants, such as Notopterygium forbesii Boiss (Zhou et al., 2007). C. virosa L. var. latisecta has potential as a source of natural insecticides for the control of the red imported fire ants.

Table 3. Controlling effectiveness of Cicuta virosa L. var. latisecta methanol extract-, chloroform fraction-, isoimperatorin- and fipronil-based baits on the inactivation of Solenopsis invicta mounds under field conditions.

\begin{tabular}{|c|c|c|c|c|c|}
\hline Treatment & \multicolumn{5}{|c|}{ Controlling effectiveness (\%) } \\
\hline $0.1 \%$ Chloroform fraction-based bait & $0.00 \pm 0.00 \mathrm{~b}$ & $31.11 \pm 5.88 b$ & $66.67 \pm 3.85 b$ & $88.89 \pm 2.22 \mathrm{ab}$ & $97.78 \pm 2.22 \mathrm{a}$ \\
\hline $0.01 \%$ fipronil-based bait & $15.56 \pm 2.22 \mathrm{a}$ & $66.67 \pm 3.85 \mathrm{a}$ & $86.67 \pm 3.85 \mathrm{a}$ & $95.56 \pm 2.22 \mathrm{a}$ & $100.00 \pm 0.00 \mathrm{a}$ \\
\hline
\end{tabular}

Values represent means from three replicates. Means within the same row followed by the same letter are not significantly different $(\mathrm{P}<0.05)$ using Scheffe's test of SAS.

\section{Acknowledgments}

The work was supported by fund from Guangdong Province for combined personnel training of the postgraduate (2013JDXM11).

\section{References}

Abbott W. S. (1925). A method of computing the effectiveness of an insecticide. Journal of Economic Entomology, 18: 265-267.
Bextine B. R., Thorvilson H. G. (2002). Field applications of bait-formulated Beauveria bassiana alginate pellets for biological control of the red imported fire ant (Hymenoptera: Formicidae). Environmental Entomology, 31: 746-752. doi: 10.1603/ 0046-225X-31.4.746.

Collins H. L., Callcott A. M. A. (1998). Fipronil: an ultralow-dose bait toxicant for control of red imported fire ants (Hymenoptera: Formicidae). Florida Entomologist, 81: 407415. doi: $10.2307 / 3495930$. 
deShazo R. D., Williams D. F. \& Moak E. S. (1999). Fire ant attacks on residents in health care facilities: a report of two cases. Annals of Internal Medicine, 131: 424-429. doi: 10.7326/0003-4819-131-6-199909210-00005

Drees B. M., Calixto A. A. \& Nester P. R. (2013). Integrated pest management concepts for red imported fire ants Solenopsis invicta (Hymenoptera: Formicidae). Insect Science, 20: 429438. doi: 10.1111/j.1744-7917.2012.01552.x

Hashimoto Y., Valles S. M. (2008) Infection characteristics of Solenopsis invictavirus 2 in the red imported fire ant, Solenopsis invicta. Journal of Invertebrate Pathology, 99:136140. doi:10. 1016/j.jip.2008.06.006

Huang T. F., Xiong Z. H. \& Zeng X. N. (2007). Studies on the contact toxicity of insecticides against the worker ants of Solenopsis invicta. Journal of South China Agricultural University, 28: 26-29. (in Chinese) doi:10.3969/j.issn.1001411X.2007.04.007

Kafle L., Wu W. J., Kao S. S. \& Shih C. J. (2011). Efficacy of Beauveria bassiana against the red imported fire ant, Solenopsis invicta (Hymenoptera: Formicidae), in Taiwan. Pest Management Science, 67: 1434-1438. doi: 10.1002/ ps. 2192

Kafle L., Wu W. J. \& Shih C. J. (2010). A new fire ant (Hymenoptera: Formicidae) bait base carrier for moist conditions. Pest Management Science, 66: 1082-1088. doi: 10.1002/ps.1981

Li Z. L., Qian S. H. \& Pu S. B. (2009). Study on chemical constituents from Cicuta virosa var. latisecta. China Journal of Chinese Materia Medica, 34: 705-707. (in Chinese) doi:10.3321/j.issn:1001-5302.2009.06.015
Lv L. H., Feng X., Cheng H. Y., Liu J., Liu X. Y. \& He Y. R. (2006). A technique for field collecting and laboratory rearing red imported fire ant, Solenopsis invicta. Chinese Bulletin of Entomology, 43: 265-267. (in Chinese) doi: 10.3969/j.issn.04528255.2006.02.034

Oi D. H., Pereira R. M., Stimac J. L. \& Wood A. (1994). Field applications of Beauveria bassiana for control of the red imported fire ant (Hymenoptera: Formicidae). Journal of Economic Entomology, 87: 623-630.

Tian Y. Q., Zhang Z. X. \& Xu H. H. (2013). Laboratory and field evaluations on insecticidal activity of Cicuta virosa L. var. latisecta Celak. Industrial Crops and Products, 41: 90-93. doi: 10.1016/j.indcrop.2012.04.015

Valles S. M., Strong C. A. (2005) Solenopsis invictavirus-1A (SINV-1A): distinct species or genotype of SINV-1? Journal of Invertebrate Pathology, 88: 232-237. doi: 10.1016/j. jip.2005.02.006

Williams D. F., Oi D. H. \& Knue G. J. (1999) Infection of red imported fire ant (Hymenoptera: Formicidae) colonies with the entomopathogen Thelohania solenopsae (Microsporidia: Thelohaniidae). Journal of Economic Entomology, 92: 830836.

Wiltz B. A., Suiter D. R. \& Gardner W. A. (2010). Activity of bifenthrin, chlorfenapyr, fipronil, and thiamethoxam against red imported fire ants (Hymenoptera: Formicidae). Journal of Economic Entomology, 103: 754-761. doi: 10.1603/EC09350

Zhou Y., Jiang S.Y., Sun H., Yang A. D., Ma Y., Ma X. J. \& Wu R. (2007). Quantitative analysis of volatile oils and isoimperatorin in Rhizoma et Radix Notopterygii. China Journal of Chinese Materia Medica, 32: 566-569. (in Chinese) doi: 10.3321/j.issn:1001-5302.2007.07.003. 